and shows that these tumors can arise at an advanced age and after a prolonged interval after transplantation.

\section{References}

1. Somers GR, Tesoriero A, Hartland E, et al. Multiple leiomyosarcomas of both donor and recipient origin arising in a heart-lung transplant patient. Am J Surg Pathol. 1998;22:1423-8.

2. Rogatsch H, Bonatti H, Menet A, Larcher C, Feichtunger H, Dirnhofer S. Epstein-Barr virus associated multicentric leiomyosarcoma in an adult patient after heart transplantation. Am J Surg Pathol. 2000;24: 614-21.

3. McClain H, Leach C, Jenson H, et al. Association of Epstein-Barr virus with leiomyoscarcomas in young people with AIDS. $N$ Engl J Med. 1995;332:12-8.

4. Knecht H, Berger C, Rothenberger S, Odermatt B, Brousset P. The role of Epstein-Barr virus in neoplastic transformation. Oncology. 2001;60: 289-302.

5. van Gelder T, Jonkman FA, Neisters HG, Vuzevzki VD, Spillenaar Bilgen EJ, Weimar W. Absence of Epstein-Barr virus involvement in an adult heart transplant recipient with epithelioid leiomyosarcoma. J Heart Lung Transplant. 1996;15:650-1.

\title{
Management of mitral paravalvular leak: Therapy or misadventure?
}

Syed Tarique Hussain, MS, Velayoudham Devagourou, MCh, and Arkalgud Sampath Kumar, MCh, New Delhi, India

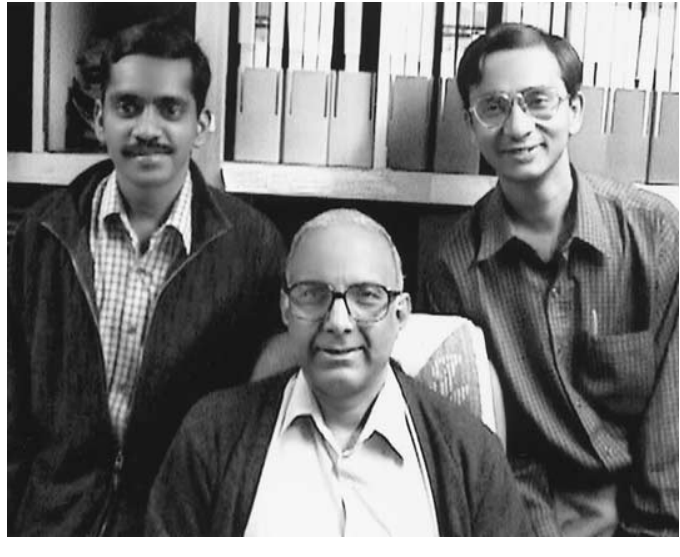

Devagourou, Sampath Kumar, Hussain

A fter mitral valve replacement, surgical closure of paravalvular leak is usually advised in severely symptomatic patients and in those requiring blood transfusion for persistent hemolysis. We present a case of persistent paravalvular leak after atrial septal defect device closure following mitral valve replacement (MVR).

\section{Clinical Summary}

A 37-year-old man with severe rheumatic mitral stenosis underwent open mitral commissurotomy on September 3, 1997. Severe mitral restenosis and increasing dyspnea developed, progressing to New York Heart Association class IV, for which he required reoperation. MVR was performed with a 3M Starr-Edwards pros-

From the Department Cardiothoracic and Vascular Surgery, All India Institute of Medical Sciences, New Delhi, India.

Received for publication March 7, 2002; accepted for publication March 25, 2003.

Address for reprints: Dr A. Sampath Kumar, Professor, Department of Cardiothoracic and Vascular Surgery, All India Institute of Medical Sciences, Ansari Nagar, New Delhi-110029, India (E-mail: asampath_kumar@hotmail.com).

J Thorac Cardiovasc Surg 2003;126:879-80

Copyright $\odot 2003$ by The American Association for Thoracic Surgery $0022-5223 / 2003 \$ 30.00+0$

doi:10.1016/S0022-5223(03)00725-6 thesis (Edwards Lifesciences, Irvine, Calif) through heart port access on June 26, 1999. One year after the operation, he had progressively increasing dyspnea on exertion, again with pedal edema and yellow discoloration of the urine and eyes. Severe mitral paravalvular leak was diagnosed. He underwent transcatheter closure of the paravalvular leak with an Amplatzer device (AGA Medical Corporation, Golden Valley, Minn) on December 4, 2001, via the right femoral vein. All the above procedures were performed at another institution.

He came to our institution with symptoms of progressively increasing dyspnea on exertion and jaundice. General physical examination revealed pallor, jaundice, pedal edema, and hepatomegaly. Cardiovascular examination revealed a loud second heart sound in the pulmonic area and a pansystolic murmur in the mitral area, a clinical picture of severe congestive heart failure. The hemogram and peripheral blood smear were consistent with hemolytic anemia. The echocardiogram revealed the mitral valve prosthesis and severe paravalvular leak with the device in situ. Cardiac catheterization and angiography (Figure 1) revealed paravalvular leak with severe mitral regurgitation and severe pulmonary venous and pulmonary arterial hypertension.

The patient underwent surgery on December 3, 2002, for replacement of the prosthesis. The intraoperative findings were consistent with the preoperative diagnosis. Both the mitral prosthesis and the device were in situ and paravalvular leak was present (Figure 2, A). The Starr-Edwards mitral valve prosthesis and device were removed (Figure 2, B) and a 31-mm St Jude Medical mitral prosthesis (St Jude Medical, Inc, St Paul, Minn) was im- 


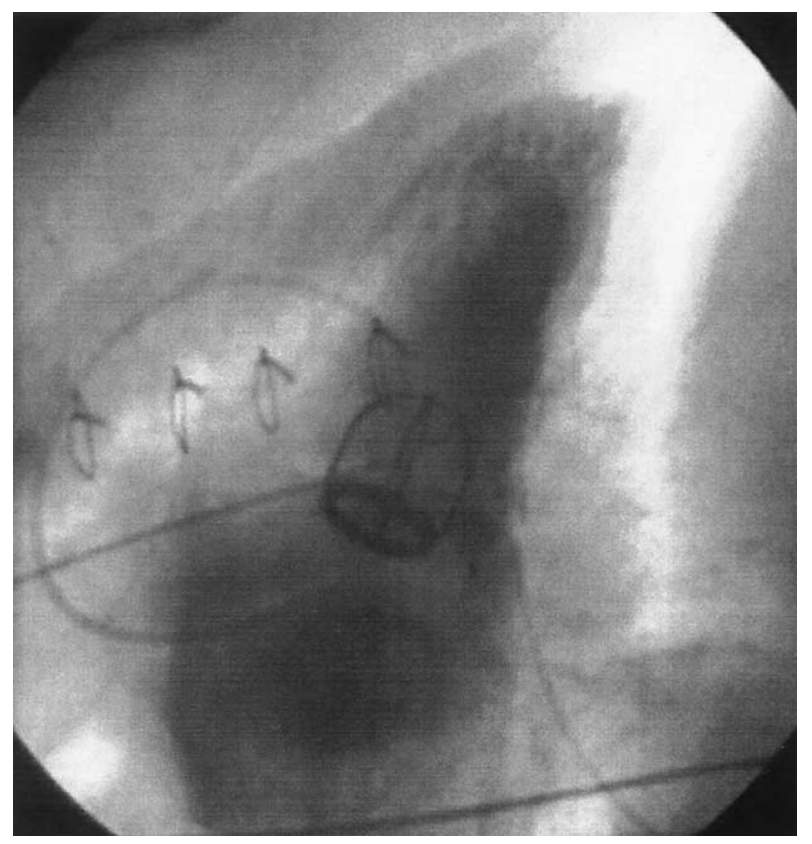

Figure 1. Left ventricular angiographic picture showing the StarrEdwards prosthesis, the Amplatzer device, and mitral regurgitation.

planted. The patient had an uncomplicated postoperative course and was discharged on the 13th postoperative day. He is now doing well 3 months after the operation.

\section{Discussion}

The management of paravalvular leak after valve replacement has been operative repair. A search of the English literature (MEDLINE, PUBMED) revealed a previous report of transcatheter device closure. Transcatheter umbrella device closure of valvular and paravalvular leaks was described by Hourihan and colleagues ${ }^{1}$ in 1992. They reported closure with a Rashkind double-umbrella device in 8 patients with high operative risk. Four patients had a paravalvular leak around a prosthetic aortic valve and 4 other patients had a valvular leak: 1 patient with a regurgitant native aortic valve after a Stansel procedure and 3 patients with a regurgitant porcine valve in a left ventricular apex-descending aorta conduit.

We did not find reports of transcatheter device closure of a mitral paravalvular leak during our search. Our patient was young and in relatively good health when he presented to us. We planned surgery because surgical fixation is the definitive management of this condition, although he had been advised reclosure with a device for the persistent paravalvular leak at the previous institution.

We believe paravalvular leak after valve replacement is best corrected by prompt reoperation. Attempts to close the eccentric,
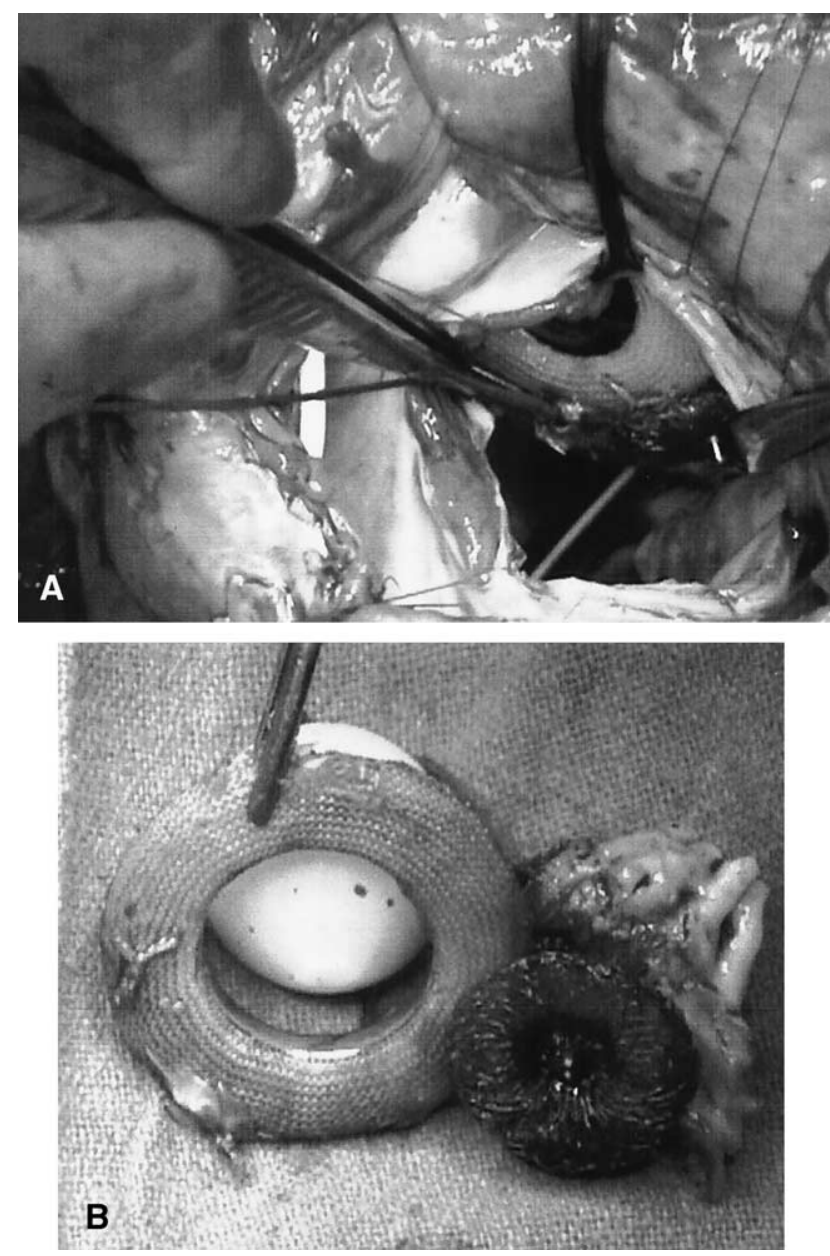

Figure 2. A, The prosthetic valve and device in situ. B, The excised prosthetic valve and device.

sometimes large defects with devices are associated with many more complications. In addition, they are generally not successful in correcting the paravalvular leak. Although it may be a technical achievement in placing such a device, especially in the mitral paravalvular area, it is best to restrict such a procedure to patients in whom contraindications exist for surgery. The effort, expense, and expert maneuvering of a device in this situation are in our opinion a futile exercise.

\section{Reference}

1. Hourihan M, Perry SB, Mandell VS, Keane JF, Rome JJ, Bittl JA, et al. Transcatheter umbrella closure of valvular and paravalvular leaks. J Am Coll Cardiol. 1992;20:1371-7. 